\title{
Exploring spatially variable relationships between NDVI and climatic factors in a transition zone using geographically weighted regression
}

\author{
Zhiqiang Zhao • Jiangbo Gao • Yanglin Wang • \\ Jianguo Liu $\cdot$ Shuangcheng Li
}

Received: 23 December 2013 / Accepted: 29 May 2014 / Published online: 12 June 2014

(C) Springer-Verlag Wien 2014

\begin{abstract}
At landscape scale, the normalized difference vegetation index (NDVI) can be used to indicate the vegetation's dynamic characteristics and has been widely employed to develop correlated and dependent relationships with the climatic and environmental factors. However, studies show that NDVI-environment relationships always emerge with complex features such as nonlinearity, scale dependency, and nonstationarity, especially in highly heterogeneous areas. In this study, we used geographically weighted regression (GWR), a local modeling technique to estimate regression models with spatially varying relationships, to investigate the spatially nonstationary relationships between NDVI and climatic factors at multiple scales in North China. The results indicate that all GWR models with appropriate bandwidth represented significant improvements of model performance over the ordinary least squares (OLS) models. The spatial
\end{abstract}

Z. Zhao $(\bowtie) \cdot$ Y. Wang $\cdot$ S. Li $(\bowtie)$

Laboratory for Earth Surface Processes Ministry of Education,

College of Urban and Environmental Sciences, Peking University,

No. 2 Yifu Building 3345, No. 5 Yiheyuan Rd, Beijing 100871,

China

e-mail: zqzhao0324@gmail.com

e-mail: scli@urban.pku.edu.cn

Y. Wang

e-mail: ylwang@urban.pku.edu.cn

J. Gao

Institute of Geographical Sciences and Natural Resources Research,

Chinese Academy of Sciences, Beijing 100101, China

e-mail: gaojiangbo@igsnrr.ac.cn

Z. Zhao $\cdot$ J. Liu

Center for Systems Integration and Sustainability, Department of

Fisheries and Wildlife, Michigan State University, East Lansing, MI 48823, USA

J. Liu

e-mail: liuji@msu.edu relationships between NDVI and climatic factors varied significantly over space and were more significant and sensitive in the ecogeographical transition zone. Clear spatial patterns of slope parameters and local coefficient of determination $\left(R^{2}\right)$ were found from the results of the GWR models. Moreover, the spatial patterns of the local $R^{2}$ of NDVI-precipitation are much clearer than the $R^{2}$ of NDVI-temperature in the semiarid and subhumid areas, which mean that precipitation has more significant influence on vegetation in these areas. In conclusion, the study revealed detailed site information on the variable relationships in different parts of the study area, especially in the ecogeographical transition zone, and the GWR model can improve model ability to address spatial, nonstationary, and scale-dependent problems in landscape ecology.

$\begin{array}{ll}\text { Abbreviations } \\ \text { GWR } & \text { Geographically weighted regression } \\ \text { OLS } & \text { Ordinary least squares } \\ \text { NDVI } & \text { Normalized different vegetation index } \\ \text { AP } & \text { Annual precipitation } \\ \text { AMT } & \text { Annual mean temperature } \\ \text { GLM } & \text { Global regression model } \\ \text { MVC } & \text { Maximum value composite } \\ \text { AIC } & \text { Akaike information criterion } \\ \text { Moran's I } & \text { Moran indexes } \\ \text { RMSEE } & \text { Root mean squared error estimate }\end{array}$

\section{Introduction}

The normalized difference vegetation index (NDVI) has been commonly used as an estimator of terrestrial vegetation distribution and productivity (Evans et al. 2006; Kerr and 
Ostrovsky 2003; Xiao and Moody 2004) and an index for monitoring green cover (Maselli and Chiesi 2006; Myneni et al. 1998). Several global and regional studies have revealed that NDVI can be used to indicate vegetation spatial-temporal characteristics (Moody and Johnson 2001; Piao et al. 2003; Wu et al. 2009; Zhang et al. 2009) and has been widely employed to quantify relationships with such climatic and environmental factors as: land surface temperature (Raynolds et al. 2008), precipitation (Fang et al. 2001; Onema and Taigbenu 2009; Piao et al. 2006), evapotranspiration (Di Bella et al. 2000), and topography (Gao et al. 2012a; $\mathrm{Li}$ et al. 2006). Since global climate change became a major topic of discussion, the relations between NDVI and climatic factors have become a hot issue in geography and ecology (Gao et al. 2012b; Li et al. 2011; Piao et al. 2006; Udelhoven et al. 2009; Xiao and Moody 2004).

Usually, general correlation and linear regression analysis were used to explore these relationships. However, a large number of studies have shown that NDVI-environment relationships always emerge with complex features such as nonlinearity, scale dependency, and nonstationarity, especially in the highly heterogeneous areas (Foody 2003, 2004; Gao et al. 2012a; Li et al. 2011; Osborne et al. 2007). In these cases, the conventional methods might fail to detect causality because their underlying assumption of linearity is violated, resulting in poor insights regarding the evolution trends of vegetation cover and underlying physical processes ( $\mathrm{Li}$ et al. 2011). Recently, as an extension of traditional standard global regression techniques, geographically weighted regression (GWR) was developed to explore spatially varying relationships (Brunsdon et al. 1998; Fotheringham et al. 2002). A few studies have confirmed the analytical efficacy of GWR for investigating spatially varying relationships in some research fields, such as climatology (Brunsdon et al. 2001), ecological inference problem (Calvo and Escolar 2003), forests (Shi et al. 2006b), urban poverty (Longley and Tobón 2004), environmental justice (Mennis and Jordan 2005), urban land surface temperature ( $\mathrm{Li}$ et al. 2010), and urban landscape fragmentation (Gao and $\mathrm{Li}$ 2011). In recent years, a limited number of studies extended its scope into relationships between vegetation and climate (Gao et al. 2012a, b; Gaughan et al. 2012; Propastin et al. 2008).

Ecogeographical transition zones are widely distributed on every continent except Antarctica and are fragile ecosystems to variations in climate. According to the Köppen climate classification (Kottek et al. 2006; Peel et al. 2007), transition zones, shifting from humid climates to desert climates, generally have semi-arid climates and exhibit some features of transition in ecological characteristics. Many scientists have focused attention on the transition zone of North China to examine the relationships between NDVI and climatic factors (Cui et al. 2009; Guo et al. 2007; Li et al. 2006; Sun and Guo 2012; Wu et al. 2009). However, few studies focused on the influences of climatic variables on vegetation in conjunction with scale dependency and spatial stationarity in this region. Considering the strong spatial heterogeneity of climatic conditions, the different effects of climate on vegetation between the transition zone and surrounding areas is worth investigating. Our concern was whether the relationship between NDVI and climatic factors was more sensitive in a transition zone than in the surrounding areas.

Our objective in this paper is to represent the spatial nonstationarity and heterogeneous features in NDVI-climate relationships at the transition zone and surrounding areas. We examined the relationships using the GWR model and compared model performance with the ordinary least squares (OLS) regression model using a geographic information system (GIS). Results related to the importance of spatial nonstationarity, scale dependency, and spatial heterogeneity of relationships are presented and discussed.

\section{Study area}

Our study area $\left(35-48^{\circ} \mathrm{N}, 112-126^{\circ} \mathrm{E}\right)$ is located in North China. The climate in this region is dominated by the winter monsoon from continental Inner Asia and the Pacific summer monsoon from the southeast. As a consequence, annual precipitation in this area decreases from the southeast to the northwest and ranges from $<100 \mathrm{~mm}$ at the west of Inner Mongolia Plateau to $>800 \mathrm{~mm}$ at the coastal zone of the Yellow Sea. The mean annual temperatures are -10 to $15{ }^{\circ} \mathrm{C}$, varying with altitude and latitude (Fig. 1).

According to the study of the ecogeographical regional system of China (Zheng 2008), this area can be divided into two temperature belts, except for Qilian Qingdong mountain basin $\left(\mathrm{HIIC}_{1}\right)$, which belongs to the plateau temperate belt, and 16 natural regions (Fig. 1 and Table 1). More detailed descriptions of the natural regions can be found in the book by Zheng (2008).

The vegetation patterns are associated with decreasing annual precipitation (AP) from southeast to northwest, as indicated in Fig. 1, changing from agricultural land, forest, and shrubland to meadow steppe, to typical steppe, and then to desert steppe. An important ecogeographical transition zone occurs where the semihumid agriculture area and arid and semi-arid pasture area meet. The ecogeographical transition zone is generally distributed along the $400 \mathrm{~mm}$ isohyet, a boundary between a semihumid monsoon climate and a semi-arid continental climate. Based on previous research (Wang et al. 1999; Zhao et al. 2002; Zheng 2008), we defined the border of the ecogeographical transition zone by using indexes including the mean AP $(\sim 300$ $450 \mathrm{~mm}$ ), rainfall variability ( 15 to $\sim 30 \%$ ), and aridity index (1.0-2.0; Fig. 1c). 
Fig. 1 Maps of the study area. a Digital elevation map of the study area (red rectangle) and surroundings. b Study area showing vegetation patterns and natural regions. $\mathbf{c}$ Map of annual mean temperature $\left({ }^{\circ} \mathrm{C}\right)$ and isohyets of annual precipitation $(\mathrm{mm})$ in the study area. $\mathbf{d}$ NDVI map of the study area with the transition zone (red dashed line)

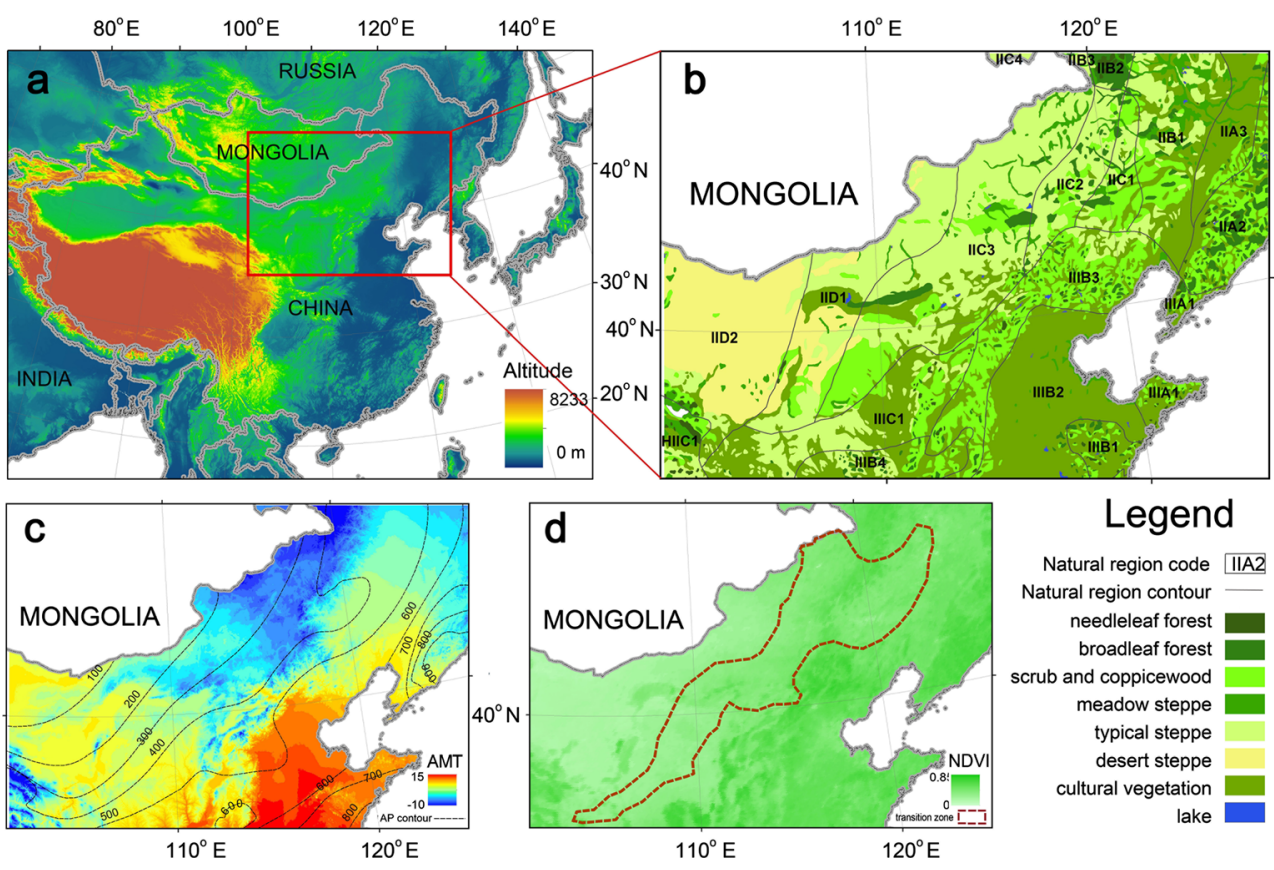

\section{Methodology}

Table 1 Natural and geographical divisions of the study area

\section{Code Natural region}

II A $A_{2}$ Lesser Xing'an Ranges Changbai mountain coniferous forest region

II $A_{3}$ East Songliao Plain pediment tableland mixed coniferous broadleaf forest region

II $\mathrm{B}_{1}$ Central Songliao Plain forest steppe region

II $B_{2}$ Central Great Xing'an Ranges mountain forest steppe region

II C $_{1}$ West Liao River Plain steppe region

II $\mathrm{C}_{2}$ South Great Xing'an Ranges steppe region

$\mathrm{II} \mathrm{C}_{3}$ East Inner Mongolian Plateau steppe region

II $\mathrm{D}_{1}$ Ordos and West Inner Mongolian Plateau desert steppe region

II $\mathrm{D}_{2} \quad$ Alxa and Hexi Corridor desert region

III A $A_{1}$ Liaodong Jiaodong hilly and lower mountain deciduous broadleaf mixed forest and revegetated region

III $B_{1}$ Luzhong hilly and lower mountain deciduous broad-leaf mixed forest and revegetated region

III $\mathrm{B}_{2}$ North China Plain revegetated region

III $B_{3}$ North China mountain mixed deciduous broad-leaf forest region

III $\mathrm{B}_{4} \quad$ Fenwei Basin deciduous broad-leaf mixed forest and revegetated region

III $\mathrm{C}_{1}$ North-central Loess Plateau steppe region

HII Qilian Qingdong mountain basin coniferous forest and steppe $\mathrm{C}_{1} \quad$ region

In natural region codes, the Roman numerals represent division of temperate zones - II is a subtemperate zone, III is a warm-temperate zone, and HII is a plateau temperate zone; the capital letters represent divisions of dry and wet areas - $\mathrm{A}$ is a humid area, B is a subhumid area, C is a semi-arid area, and $\mathrm{D}$ is an arid area. The subscript numbers $1-4$ represent different nature regions which are divided according to the physiognomy and the terrain

\subsection{Data}

\subsubsection{Dependent variable: NDVI}

For this study, NDVI was employed as the dependent variable of GWR and OLS models in this study. As one of the most widely used indices for green cover monitoring, NDVI is computed as the ratio of two electromagnetic wavelengths; $\mathrm{NDVI}=(N-R) /(N+R)$, where $N$ refers to the spectral reflectance in the near infrared, where reflectance from the plant canopy is dominant, and $R$ is the reflectance in the red portion of the spectrum, where chlorophyll absorbs maximally. The NDVI series of satellite observations about $1 \mathrm{~km}^{2}$ spatial and 10-day (decades) temporal resolution were produced by the Vlaamse Instelling voor Technologisch Onderzock (VITO) Image Processing Centre (Mol, Belgium) from the sensor VEGETATION on board the SPOT-4 satellite (http://free. vgt.vito.be/). VGT-S10 NDVI were synthesized from S1 (1day resolution) NDVI products using a maximum value composite (MVC) algorithm (Jarlan et al. 2008). The influence of cloud cover was well reduced because the highest signal data within the 10-day observation was used as a pixel value for the 10-day synthesis data. The VGT-S10 products were compiled by merging segments (data strips) acquired over a 10-day period. All the segments of this period were compared again pixel by pixel to pick out the "best" ground reflectance values. In addition, the processing of VGT-S10 products also included the application of corrections for radiometric, atmospheric, and geometric effects. For this study, we generated the annual 
maximum NDVI image of 2008 to represent the spatial distribution of NDVI in the study area by using the maximum value composite (MVC) method.

\subsubsection{Explanatory variable: climatic factors}

Explanatory variables were obtained from the WorldClim Database (Hijmans et al. 2005), which was produced by the University of California, Berkeley, in the USA and the University of Queensland in Australia. This database is a set of global climate layers (climate grids) with a spatial resolution of about $1 \mathrm{~km}^{2}$ using a smoothing thin-plate spline interpolation method, and included 47,554 mean precipitation data entries, 24,542 mean temperature entries, and 14,835 minimum and maximum temperature data entries gathered from a variety of sources and restricted mostly for the 1950-2000 period.. It includes 19 derived bioclimatic variables and is commonly used to represent the annual average trends. The database can be downloaded from the WorldClim Website (http://www.worldclim.org/).

We used Pearson correlation analysis and mutual information entropy analysis to describe the relationships between 19 climatic factors and NDVI. And the results showed that AP (BIO12 in the WorldClim database) and Annual Mean Temperature (AMT, BIO1 in the WorldClim database) were the best explanatory variables to estimate the relationship across the whole study area.

\subsection{Geographically weighted regression}

\subsubsection{Brief description of GWR}

As one of several local regression techniques, GWR is an extension of traditional standard global regression techniques such as OLS regression. Fotheringham et al. (2002) provide a detailed description of the algorithm and the principle of GWR. Hence, we give only a brief overview of GWR in this section.

Consider that the conventional global regression model (GLM) could be expressed as:

$y_{i}=\beta_{0}+\sum_{k} \beta_{k} x_{i k}+\varepsilon_{i}$

where $y_{i}, x_{i k}$, and $\varepsilon_{i}$, respectively, represent the dependent variable, the independent variables, and the random error term at different locations (the subscript $i$ stands for the spatial locations and $k$ expresses the independent variable number). $\beta_{0}$ is the model intercept and $\beta_{k}$ is the slope coefficient for independent variable $x_{k}$. This type of model implies a spatially stationary relationship, i.e., no geographical location information is considered in the estimation of the model parameters, and gives a single summary statistic for the whole dataset.
The GWR technique extends the conventional global regression of Eq. (1) by adding a geographical location parameter, with the model rewritten as:

$y_{i}=\beta_{0}\left(u_{i}, v_{i}\right)+\sum_{k} \beta_{k}\left(u_{i}, v_{i}\right) x_{i k}+\varepsilon_{i}$

where $\left(u_{i}, v_{i}\right)$ denotes the coordinates of the $i$ th point in space, $\beta_{0}\left(u_{i}, v_{i}\right)$ is the intercept for location $i$, and $\beta_{k}\left(u_{i}, v_{i}\right)$ represents the local parameter estimate for independent variable $x_{k}$ at location $i$, and again $\varepsilon_{i}$ is the random error term at point $i$.

In Eq. (2), $\beta_{0}$ and $\beta_{k}$ are parameters to be estimated, and could be estimated from:

$\beta\left(u_{i}, v_{i}\right)=\left(X^{T} W\left(u_{i}, v_{i}\right) X\right)^{-1} X^{T} W\left(u_{i}, v_{i}\right) y$

where $\widehat{\beta}\left(u_{i}, v_{i}\right)$ represents the unbiased estimate of the regression coefficient $\beta, W\left(u_{i}, v_{i}\right)$ is the weighting matrix to ensure that observations near the specific point have larger weight value, and $X$ and $Y$ are matrices for independent and dependent variables, respectively.

Weighting the kernel function could be stated using the exponential distance decay form:

$w_{i j}=\exp \left(-\frac{d_{i j}}{b^{2}}\right)$

where $w_{i j}$ represents the weight of observation $j$ for location $i$, $d_{i j}$ is the Euclidean distance between regression point $i$, and neighboring observation $j$, and $b$ expresses a basal width of the kernel function, called bandwidth. In Eq. (4), if $j$ coincides with $i$, the weighting value of the data at that point is set to 1 , while $w_{i j}$ is decreasing according to a Gaussian curve as the distance $d_{i j}$ increases (Fotheringham et al. 2002; Shi et al. 2006a), and the weight would be set to 0 if the distance is greater than the kernel bandwidth.

By adding the geographical location parameter, a separate GWR model can be run for each observation point, and parameter estimates obtained by weighting all observations around a specific point $i$ based on their spatial proximity to it. Larger weights are assigned to observations closer to point $i$, and these observations have higher impacts on the parameter estimates for the location. Precisely because GWR obtains local rather than global parameter estimates (Fotheringham et al. 2002), its estimates are not constant but vary over space; therefore, it could help to show the hidden causes of vegetation patterns.

In our study, GWR analysis was performed using ArcGIS 9.3 (ESRI Inc., 1999-2008) software, and all maps were produced using the same software. 


\subsubsection{Data sampling}

Both dependent and independent variables were initially raster layers with $1-\mathrm{km}$ spatial resolution and had to be converted to vector format to meet the requirements of ArcGIS-based GWR. Three steps converted the data format (Gao et al. 2012a; Li et al. 2010): (1) sampling points in the study area were generated randomly; (2) values were extracted from original raster data layers to points; and (3) points with variables were chosen for GWR model. In this study, a total of 6,485 data points were used in the GWR model after removing NoData cases.

\subsubsection{Measuring nonstationarity}

The spatial nonstationarity of ecological variables and their relationships were scale-dependent (Foody 2004; Li et al. 2010). Somewhat similar to a spatial microscope, the GWR model provided useful information at different resolutions by varying the bandwidth parameter. More generalized geographical patterns were revealed as the bandwidth coarsened, and the spatial nonstationarity in the relationship tended to decline (Li et al. 2010).

In our study, a stationarity index proposed by Brunsdon et al. (1998) and Osborne et al. (2007) was used to estimate spatial nonstationarity. It is computed as follow:

$\mathbf{S I}=\frac{\beta_{\text {GWR_iqr }}}{2 \times \text { GLM_Se }}$

where $\mathrm{SI}$ is the stationarity index, $\beta_{\mathrm{GWR} \text { iqr }}$ is the interquartile range of standard errors for the GWR coefficients, and GLM se is the standard error of the global regression coefficient. When $\mathrm{SI}<1$, the explanatory variable $y$ and dependent variable $x$ reach spatial stationarity (Gao and Li 2011). To identify the scale dependence of spatial nonstationarity in local parameter coefficients, we iterated the GWR model with increasing fixed kernel bandwidth from 25 to $1,500 \mathrm{~km}$ as the search radius. The SI was calculated using Matlab 2008B (The MathWorks Inc., Natick, MA, USA).

\subsubsection{Model test}

GWR model is equivalent to the global regression model if the localized parameter estimates do not have statistically significant differences (Gao et al. 2012b; Li et al. 2010), therefore, a statistical significance test of the spatial nonstationarity was necessary.

We used the corrected Akaike information criterion $\left(\mathrm{AIC}_{\mathrm{c}}\right)$ (Hurvich and Tsai 1989; Akaike 1973), a relative measure of model performance, to compare performances of GWR and OLS models.

$\mathrm{AIC}_{c}=2 n \ln (\widehat{\sigma})+\mathrm{n} \ln (2 \pi)+\mathrm{n}\left(\frac{n=\operatorname{tr}(S)}{n-2-\operatorname{tr}(S)}\right)$

where $n$ is the number of the sample size, $\hat{o}$ is the estimate of the standard deviation of the residuals, and $\operatorname{tr}(S)$ is the trace of the hat matrix. The model with the lower $\mathrm{AIC}_{\mathrm{c}}$ value indicated better fit to the observed data and superior performance. Generally, a decrease in $\mathrm{AIC}_{\mathrm{c}}$ values to lower than 3 indicated that the model with the lower $\mathrm{AIC}_{\mathrm{c}}$ was better.

Furthermore, global and local Moran indexes (Moran's I) of residuals of the GWR and OLS models were calculated in ArcGIS 9.3 to compare the ability to deal with spatial autocorrelation. Moran's $I$ values ranged from -1 to 1 , and the larger the absolute value of Moran's $I$, the more significant the spatial autocorrelation. Moreover, sigma ${ }^{2}$, the normalized residual sum of squares (the smaller the values, the closer the fit of the model to the observed data) was calculated to compare the two models. The F3 test (Leung et al. 2000) was also calibrated for the GWR model.

\section{Results}

\subsection{Scale dependence of spatial relationships}

As shown in Fig. 2, the variational trends of the stationarity index for AMT and AP exhibited significant spatial scale dependence. The stationarity index decayed rapidly with the coarsening of the scale for both explanatory variables, and the decline slopes of the curves became flat above the spatial scale of $400 \mathrm{~km}$. Compared with AMT, the curve for AP had not only a bigger decline gradient but also relatively larger stationarity index values. The fact that different predictors had different stationarity index values suggested that the NDVI
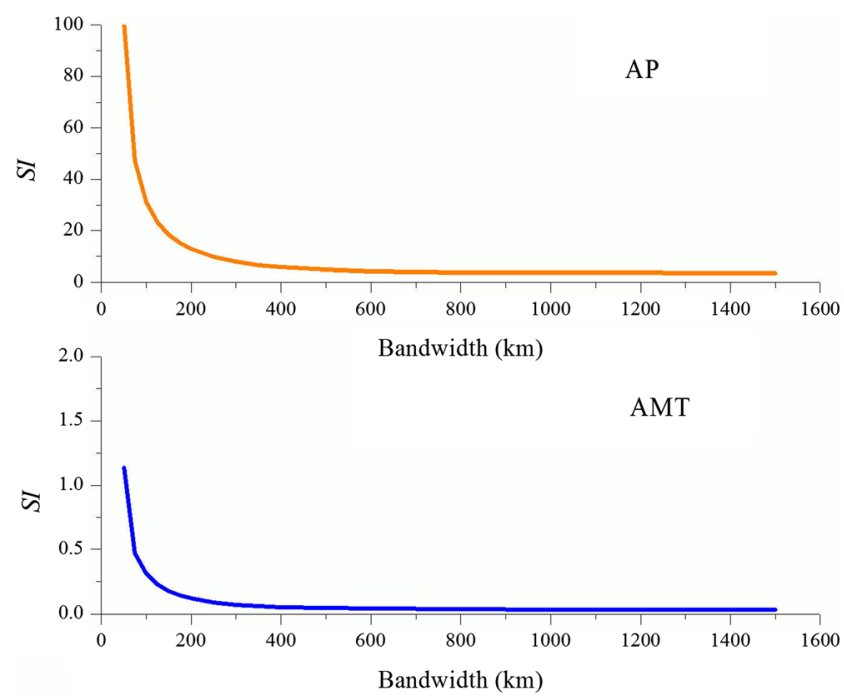

Fig. 2 Stationarity indexes at multiple scales for two explanatory variables. The stationarity index is a ratio between the interquartile range of standard error for GWR coefficients and twice the standard error for a global regression analysis such as OLS, and values smaller than 1 indicates stationarity. The most striking difference between SI for MAP ( 0 to 99.3 ) and MAT ( 0 to 0.95 ) is the numeric range 
spatial pattern was dominated by climatic factors at different spatial scales.

Within the whole study area spatial scale range, the relationships between NDVI and AMT and between NDVI and AP tended to stabilize at the scales of 50 and $500 \mathrm{~km}$, respectively. The results indicated that if we want to establish a stationary regression relationship between NDVI and AMT and AP, a bandwidth of 50-500 km was suitable. According to cross-validation and corrected AIC, a GWR model with $430 \mathrm{~km}$ as the bandwidth was most appropriate for our study area.

\subsection{The spatial patterns of NDVI-climate relationships}

Maps of slope parameters (beta coefficients), local $R^{2}$, and intercept (alpha coefficients) obtained from GWR models provided a simple way to detect the spatially varying relationships between NDVI and climatic factors. As shown in Fig. 3, there was significant spatial heterogeneity in the relationships between NDVI and AP and AMT.

Regression correlation coefficients, ranging from 0 to 1 , were used to indicate how well the local regression model fit the observations, and the local models with higher values perform better. The spatial pattern of local $R^{2}$ (Fig. 3d) indicated that higher values $\left(R^{2}>0.45\right)$ occurred in the transition zones (Table 2). However, in the northwest and southeast of the study area, the Alxa and Hexi Corridor desert and revegetated region, respectively, the correlation coefficients were lower, which indicated that other factors had more influence on NDVI.

AP had a positive correlation with NDVI in most of our study area (Fig. 3a), which indicated that higher NDVI values were related to more precipitation. However, slope parameters, local $R^{2}$, and intercept obtained from GWR were not spatially consistent, which meant that the strength of correlation varied across space (Fig. 3a and Table 2). Beta of AP in transition zones (mean $=0.0013, \mathrm{SD}=0.0003$ ) was greater than that in surrounding areas, especially more than twice as many holdouts as in humid areas (mean $=0.0006, \mathrm{SD}=0.0005$ ). Compared with AP, positive and negative correlations were observed between NDVI and AMT by the GWR model (Fig. 3b). In addition, the strength of the association of temperature also varied across space (Fig. 3b and Table 2). Furthermore, a comparison of Fig. 3a with $b$ showed that the patterns of the strength of AP exhibited obvious regularity. However, the spatial patterns of the strength of AMT were more complicated, showing no regular distribution along the climatic conditions. This result indicated that, in semi-arid and subhumid areas, transitioning from humid climates to arid climates, precipitation had more significant influence on NDVI distribution than temperature.

\subsection{Spatial heterogeneity of relationships}

As the study area covered a wide-ranging geographical region, the local natural and environmental conditions had huge variations. In Sections 4.1 and 4.2, we described how the spatial scales of stationarity, $R^{2}$, slope parameters, and intercepts obtained from the GWR model (Figs. 2 and 3, Table 2) had primarily shown the spatial variance of the relationships between NDVI and climatic factors. In this section, we discuss how GWR and OLS models were run in each natural region based on the natural and geographical divisions of China (Zheng 2008) (Fig. 1a). As shown in Table 3, the model performances were inconsistent among regions, which indicated the spatial heterogeneity of relationships.

The performance of the regression relationships between NDVI and AMT and AP were better in grassland and meadow areas, which indicated that the influence of climatic factors on NDVI was relatively stable in these regions. However, both GWR and OLS models' regression performances were very poor in some areas (e.g., Liaodong Jiaodong hilly and lower mountain deciduous broad-leaf mixed forest and revegetated region $\left(\right.$ IIIA $\left._{1}\right)$, Luzhong hilly and lower mountain deciduous broad-leaf mixed forest and revegetated region $\left(\mathrm{IIIB}_{1}\right)$, and the North China Plain revegetated region $\left.\left(\mathrm{IIIB}_{2}\right)\right)$. Thus, other climatic factors besides AMT and AP might be better explanatory variables explaining the distribution of NDVI in these regions. Moreover, in the transition zones, such as the central Great Xing'an Ranges mountain forest steppe region $\left(\mathrm{IIB}_{2}\right)$, Qilian Qingdong mountain basin coniferous forest and steppe region $\left(\mathrm{HIIC}_{1}\right)$, east Songliao Plain pediment tableland mixed coniferous broad-leaf forest region $\left(\mathrm{IIA}_{3}\right)$, and Ordos and West Inner Mongolian Plateau desert steppe region (IID 1$)$, the GWR models performed better than the OLS models.

\subsection{Comparisons between OLS and GWR models}

\subsubsection{Model performance}

The $\mathrm{AIC}_{\mathrm{c}}, R^{2}$, and sigma ${ }^{2}$ of GWR and OLS models are shown in Table 4. In all cases, the GWR model yielded more accurate simulation results, characterized by higher $R^{2}$ values, lower $\mathrm{AIC}_{\mathrm{c}}$ values, and lower sigma ${ }^{2}$ values of the GWR models. With AMT and AP as explanatory variables, the $R^{2}$ of the GWR model was 0.84 , compared with 0.69 for OLS; the $\mathrm{AIC}_{\mathrm{c}}$ of GWR was $-15,491.47$, lower than the OLS value of $-9,671.21$; the Sigma $^{2}$ of GWR was 0.0103 , also lower than the OLS value of 0.0199 . As indicated by the $R^{2}$ values, AMT could only explain less than $1 \%$ of the variance in NDVI in the OLS model, while it can account for almost $80 \%$ of the variance in GWR. Since the vegetation patterns of the study area were mainly associated with the $\mathrm{AP}$ patterns, all $\mathrm{AIC}_{\mathrm{c}}, R^{2}$ and sigma ${ }^{2}$ values indicated that both OLS and GWR models for NDVI and precipitation showed significantly better 

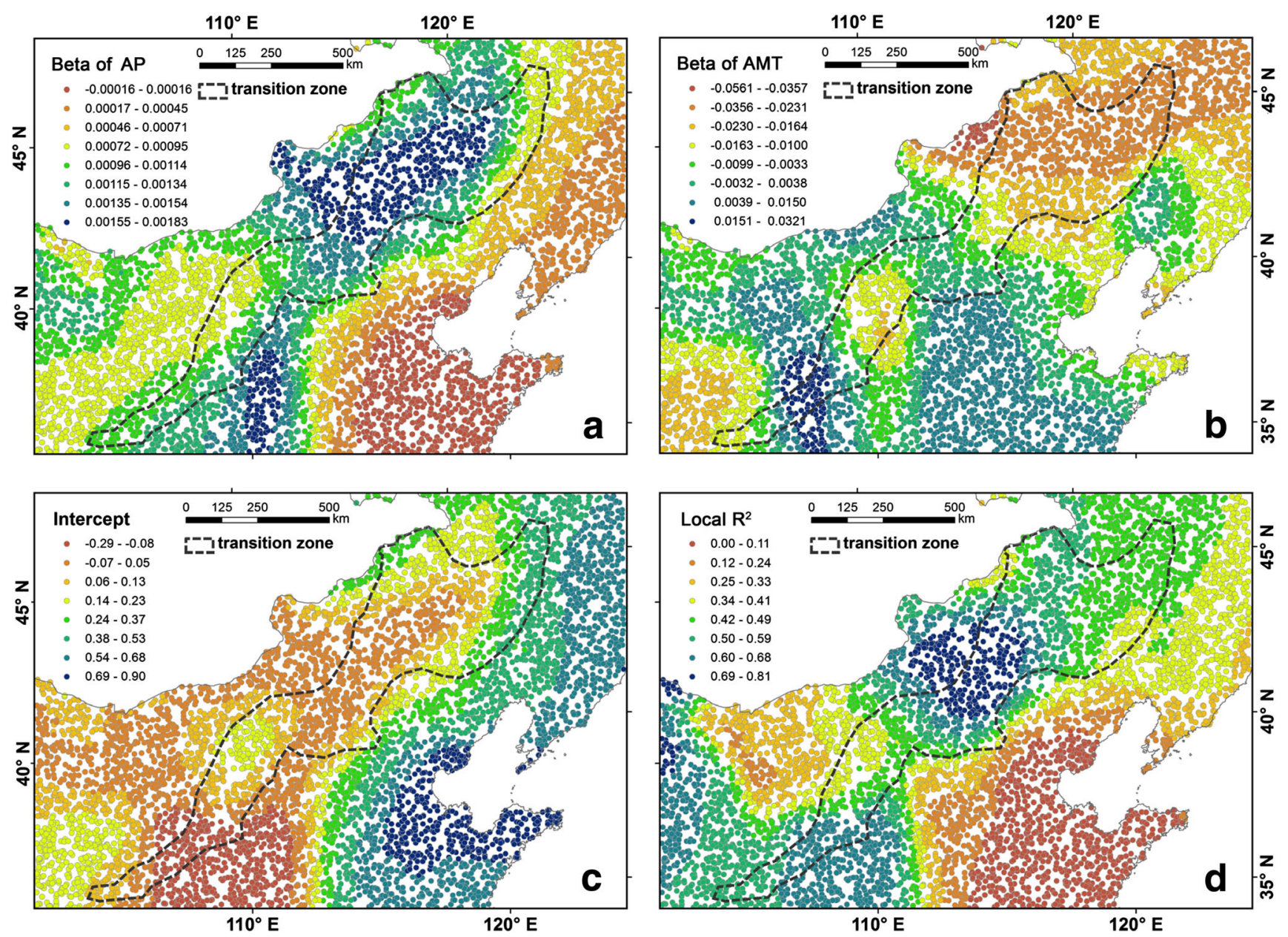

Fig. 3 Spatial variation of regression outputs from the GWR models for NDVI and climatic variables in the study area $-\mathbf{a}$ beta of AP, $\mathbf{b}$ beta of AMT, $\mathbf{c}$ intercept, d local $R^{2}$

performance than models for NDVI and temperature. Likewise, AP could explain more than $83 \%$ of the variance in NDVI in the GWR model, compared with $63 \%$ in the OLS model. Furthermore, the results of F3 tests (not shown) also indicated that the improvement of the GWR models over their corresponding OLS models was statistically significant based on 500 sampling points.

Table 2 Comparison of GWR model outputs between the transition zone and nontransition zones (east and west sides). An independent-samples $t$ test was conducted to compare mean values for regression outputs in the

\begin{tabular}{|c|c|c|c|c|c|c|}
\hline \multirow[t]{2}{*}{ Regression outputs } & \multicolumn{2}{|c|}{ Transition zone } & \multicolumn{2}{|l|}{ East side } & \multicolumn{2}{|l|}{ West side } \\
\hline & Mean & SD & Mean & SD & Mean & SD \\
\hline Beta of AP & 0.0013 & 0.0003 & 0.0006 & 0.0005 & 0.0010 & 0.0002 \\
\hline Beta of AMT & -0.0138 & 0.0136 & -0.0058 & 0.0121 & -0.0064 & 0.0118 \\
\hline Intercepts & 0.1074 & 0.1499 & 0.3851 & 0.2902 & 0.0608 & 0.0753 \\
\hline local $R^{2}$ & 0.5266 & 0.1082 & 0.3006 & 0.1979 & 0.4864 & 0.1538 \\
\hline
\end{tabular}

\subsubsection{Spatial autocorrelation of residuals}

Autocorrelation is an expression of the lack of independence between pairs of observations at given distances apart, in time and in space (Legendre 1993). Generally, the high randomness of simulated residuals and the cumulative residual amount indicated better performance of the regression model. The

transition zone and nontransition zones. There were significant differences $(p<0.01)$ in the beta of MAP, beta of MAT, intercepts, and local $R^{2}$ between the transition zone and nontransition zones 
Table 3 Regression correlation coefficients of GWR and OLS models in natural regions

\begin{tabular}{|c|c|c|c|c|c|}
\hline Region code & Mean Local $R_{\mathrm{G}}^{2}$ & Minimum Local $R_{\mathrm{G}}^{2}$ & Maximum Local $R_{\mathrm{G}}^{2}$ & $R_{\mathrm{O}}^{2}$ & $\operatorname{Adj} R^{2}$ \\
\hline $\mathrm{IIA}_{2}$ & 0.3461 & 0.2631 & 0.3989 & 0.416 & 0.412 \\
\hline $\mathrm{IIA}_{3}$ & 0.3996 & 0.3730 & 0.4266 & 0.028 & 0.019 \\
\hline $\mathrm{IIB}_{1}$ & 0.4263 & 0.3255 & 0.4716 & 0.309 & 0.307 \\
\hline $\mathrm{IIB}_{2}$ & 0.4815 & 0.4556 & 0.5059 & 0.270 & 0.246 \\
\hline $\mathrm{IIC}_{1}$ & 0.4384 & 0.3762 & 0.5227 & 0.467 & 0.461 \\
\hline $\mathrm{IIC}_{2}$ & 0.5397 & 0.4368 & 0.7017 & 0.547 & 0.544 \\
\hline $\mathrm{IIC}_{3}$ & 0.5486 & 0.2614 & 0.7988 & 0.469 & 0.468 \\
\hline $\mathrm{IID}_{1}$ & 0.4772 & 0.2618 & 0.7449 & 0.024 & 0.020 \\
\hline $\mathrm{IID}_{2}$ & 0.4525 & 0.2156 & 0.8149 & 0.472 & 0.471 \\
\hline IIIA $_{1}$ & 0.1205 & 0.0013 & 0.2911 & 0.107 & 0.092 \\
\hline $\mathrm{IIIB}_{1}$ & 0.0077 & 0.0011 & 0.0122 & 0.090 & 0.074 \\
\hline $\mathrm{IIIB}_{2}$ & 0.0357 & 0.0001 & 0.1945 & 0.052 & 0.049 \\
\hline $\mathrm{IIIB}_{3}$ & 0.2664 & 0.0341 & 0.5423 & 0.174 & 0.172 \\
\hline $\mathrm{IIIB}_{4}$ & 0.5327 & 0.1516 & 0.6764 & 0.249 & 0.242 \\
\hline $\mathrm{IIIC}_{1}$ & 0.5183 & 0.2042 & 0.6797 & 0.604 & 0.603 \\
\hline $\mathrm{HIIC}_{1}$ & 0.5897 & 0.5551 & 0.6235 & 0.019 & 0.001 \\
\hline
\end{tabular}

Subscript G represents GWR; subscript O represents OLS

spatial distribution of the simulated residuals of the GWR and OLS models are shown in in Fig. 4. As illustrated, the simulated residuals of the OLS model showed lower random distribution than those of the GWR model.

The global Moran's $I$ analysis of model residuals is shown in Table 5 and confirms the improved performance of the GWR model over the OLS model. Significant positive spatial autocorrelations were detected in the residuals from all runs of the OLS model, characterized by Moran's $I$ values ranging from 0.732 to 0.917 at $p<0.01$, and the GWR model residuals had weaker significant spatial autocorrelation patterns (Moran's I ranging from 0.522 to 0.610 at $p<0.01)$. With the same independent variable, GWR models produced smaller Moran's $I$ than OLS models, which indicated that GWR models

Table 4 Comparison of model performance between GWR and OLS

\begin{tabular}{llll}
\hline Indicator & Temp & Prec & Temp + Prec \\
\hline $\mathrm{AICc}_{\mathrm{O}}$ & -882.11 & $-8,087.07$ & $-9,671.21$ \\
$\mathrm{AICc}_{\mathrm{G}}$ & $-13,347.34$ & $-14,940.01$ & $-15,491.47$ \\
$R_{\mathrm{O}}^{2}$ & 0.0070 & 0.6357 & 0.6949 \\
$R_{\mathrm{G}}^{2}$ & 0.7985 & 0.8314 & 0.8417 \\
$R_{\mathrm{O}}^{2}$ adjusted & 0.0069 & 0.6356 & 0.6948 \\
$R_{\mathrm{G}}^{2}$ adjusted & 0.7980 & 0.8309 & 0.8412 \\
Sigma $_{\mathrm{O}}$ & 0.0646 & 0.0237 & 0.0199 \\
Sigma $_{\mathrm{G}}^{2}$ & 0.0131 & 0.0110 & 0.0103 \\
\hline
\end{tabular}

The subscript $\mathrm{O}$ in the index represents OLS, and G represents GWR represented more reliable relationships by reducing the spatial autocorrelations of residuals. The value for precipitation was smaller than the value for temperature, corresponding to the results of model performance.

\subsubsection{Predicted NDVI patterns}

Figure 5 shows the NDVI spatial patterns observed and predicted by the GWR and OLS models. In order to compare the predicted and observed NDVI values, the root mean squared error estimate (RMSEE) was calculated to compare the two models. In general, both models predicted similar overall patterns that NDVI values would decrease from southeast to northwest of in the study area. However, comparing the actual spatial pattern of NDVI (Fig. 5a), the pattern predicted by GWR (Fig. 5b, RMSEE $=0.094$ ) was more precise than the spatial pattern estimated by the OLS model in the whole study area (Fig. 5c, RMSEE=0.141). The OLS model tended to overestimate the NDVI values, especially in the southeast, where OLS estimated NDVI values would be up to 1.36 although the real values were only about 0.9 . Furthermore, by comparing the spatial pattern of NDVI predicted by GWR and the spatial pattern estimated by the OLS model in each natural region (Fig. 5d, RMSEE=0.103), we could see that both results were quite similar to real spatial patterns. Modeling and taking into consideration the heterogeneity of the regional and subregional conditions were achieved by using the GWR model; therefore, this local regression model showed significant 

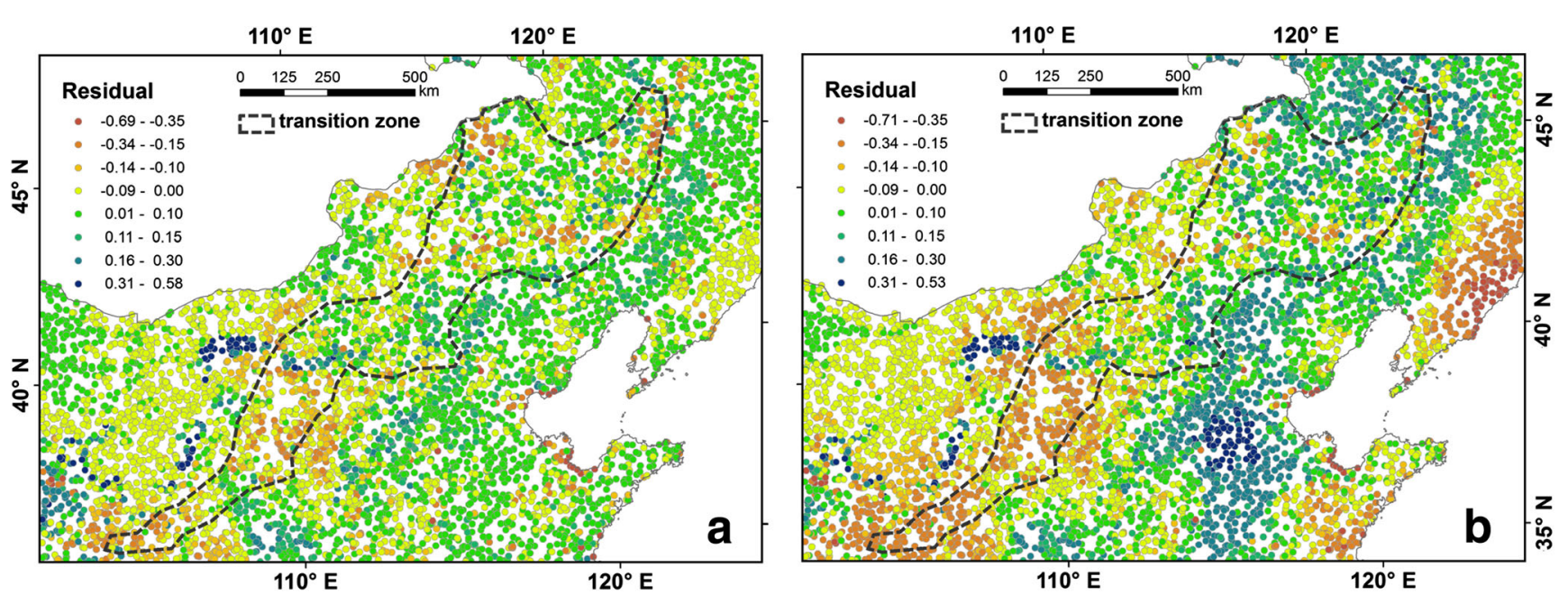

Fig. 4 The spatial distribution of the simulated residuals of the GWR model (a) and OLS model (b)

improvement over the OLS model with the same predictor and proved to be practical for similar applications and expansions.

\section{Discussion}

The results of this study showed significant spatial heterogeneity in the relationship between NDVI and climatic factors. Previous research had reported that the variations in NDVI and its correlation with temperature and precipitation in different climatic zones and land use types were spatially heterogeneous (Cui et al. 2009; Sun and Guo 2012). Thus, it was unreasonable to assume that a single set of regression coefficients could capture space-varying and scale-dependent relationships between variables when conducting large-scale analysis (Finley 2011). The findings on spatial relationship between NDVI and climatic factors were basically consistent with several other studies. In some subarea studies, Liu et al. (2008) showed that NDVI variability had significant positive correlation with annual precipitation and insignificant negative correlation with annual precipitation at Tianjin,

Table 5 Comparison of Moran's Index (MI) of residuals between OLS and GWR models

\begin{tabular}{lllll}
\hline Explanatory variables & $\mathrm{MI}_{\mathrm{O}}$ & $p$ value & $\mathrm{MI}_{\mathrm{G}}$ & $p$ value \\
\hline Temperature & 0.917 & 0.01 & 0.610 & 0.01 \\
Precipitation & 0.763 & 0.01 & 0.551 & 0.01 \\
All variables & 0.732 & 0.01 & 0.522 & 0.01 \\
\hline
\end{tabular}

Subscript O represents OLS, subscript G represents GWR, and $p$ value is the pseudosignificance level and $\mathrm{Wu}$ et al. (2009) found that variability of precipitation had the most important influence on NDVI variation in Shanxi Province. In our study, we found that AP had a positive correlation with the NDVI for almost the entire study area; however, both positive and negative correlations were observed between NDVI and AMT (Fig. 3). Regardless of the positive or negative association of NDVI with AMT and AP, the associations were stronger for the transition zone (Table 2), where vegetation distribution was more sensitive to climatic conditions. This result corresponded to previous findings in eastern China in that it showed stronger correlations between NDVI and temperature and precipitation in the midtemperature semiarid zone (Cui et al. 2009). Therefore, the transition zone with vulnerability (Lamb and Mallik 2003) and sensitive spatiotemporal dynamics properties (Ross et al. 2003) needs further investigation in the future.

Meanwhile, we found that the correlation between NDVI and AMT and AP was not significant in some regions, especially the southeast study area with relatively wet conditions and higher human activity. Previous studies suggested that human activity is a major force affecting the vegetation change. For instance, Morawitz et al. (2006) conducted a longitudinal study and found that population density was highly correlated with negative NDVI change 15 years in central Puget Sound. On a spatially distribution perspective, however, studies showed strong positive correlations between human population density and NPP (Balmford et al. 2001; Chown et al. 2003). Luck (2007) explained that it was because humans tend to settle in areas with midhigh productivity. In addition to economic growth and human population density, agricultural irrigation also has effects on the distribution of NDVI. However, the irrigation amount for agriculture significantly varies with annual precipitation and its seasonal distribution. In the study area, the rainy days and precipitation 

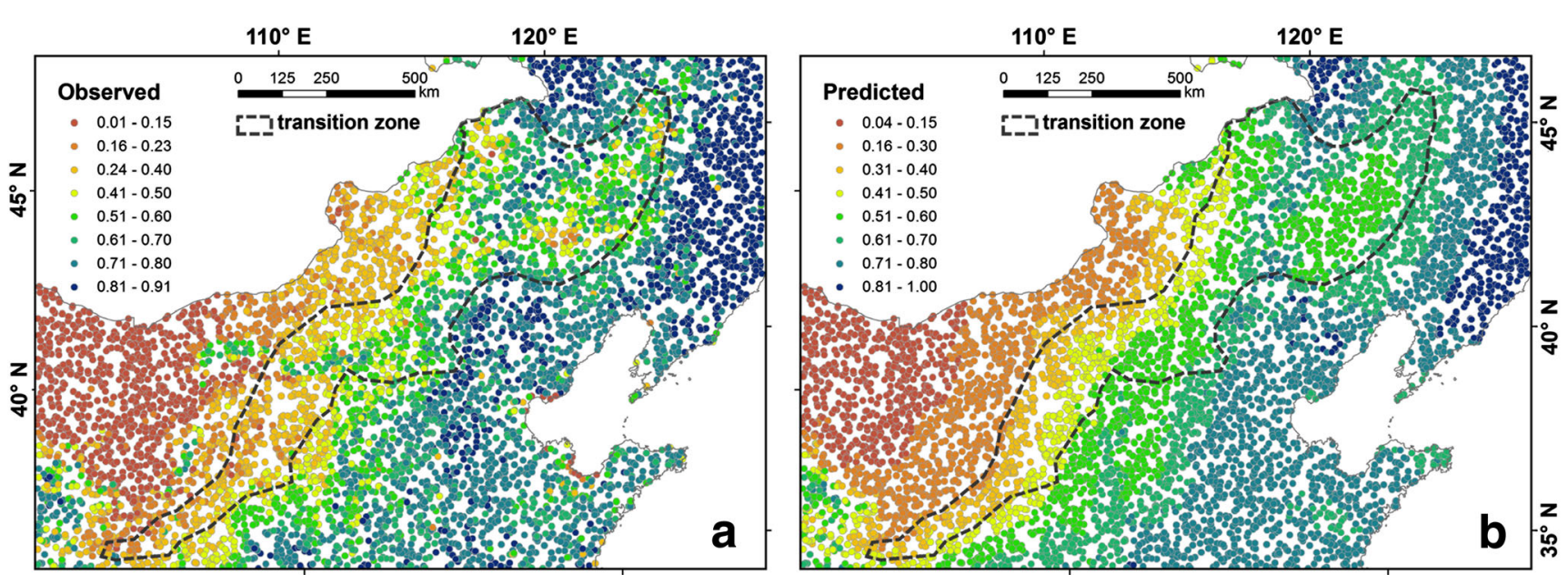

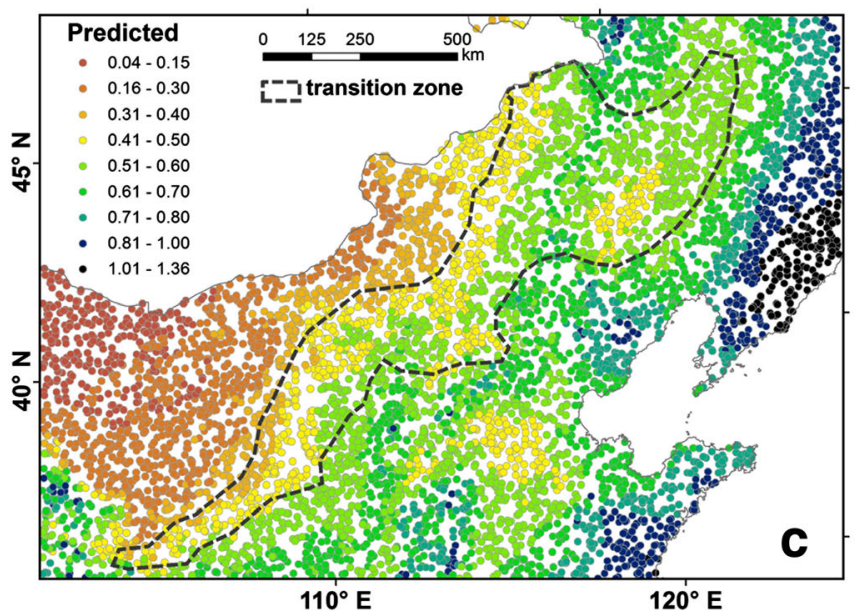

Fig. 5 Comparison of predicted NDVI between GWR and OLS models. a The true spatial pattern of NDVI in the study area. $\mathbf{b}$ The spatial patterns of NDVI predicted by the GWR. $\mathbf{c}$ The spatial patterns of NDVI predicted

amount are mainly concentrated in summer and coincide with the summer maize growing season. Previous study has shown that the crop water requirement for summer maize was about $430 \mathrm{~mm}$ (Sun et al. 2010), which explained why precipitation was not the determinant which affected the NDVI value in these regions. The distribution of vegetation is affected synthetically by various factors, but effects of influences on vegetation are different in scales. Human activities may result in the disruption of ecological communities, while the climatic factors are critical for the spatial variations of vegetation on large scales.

An appropriate scale was very important in analyzing the spatial data. One of the fundamental concepts of geography is distance decay, which was once called the "First Law of Geography": Everything is related to everything else, but near things are more related than distant things (Tobler 1970). Based on this principle, GWR employs a weighted matrix generated by Gaussian function at each regression point in the space. Choosing a suitable kernel bandwidth parameter is crucial in analyzing the spatial data. Thus, before

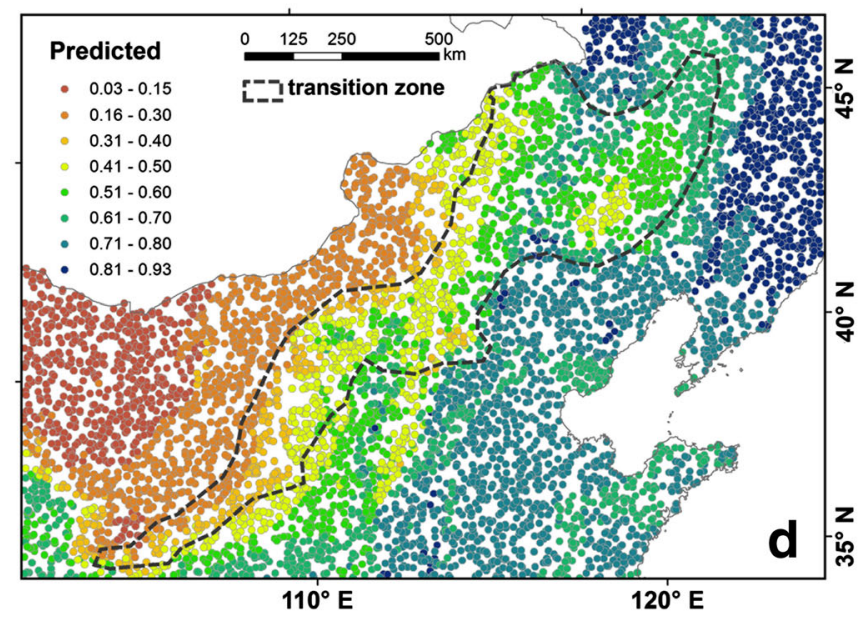

by the OLS model. $\mathbf{d}$ The spatial patterns of NDVI predicted by the OLS models in all natural regions

implementing GWR models, the kernel function and corresponding bandwidth should be determined (Guo et al. 2008). In ArcGIS-based GWR models, there are two options for bandwidth parameter-self-adaptive and fixed. Many studies about the relationship between vegetation and climate, such as the studies of Gao et al. (2012a, b), Gaughan et al. (2012), Propastin et al. (2008), were carried out using a fixed bandwidth, since a fixed bandwidth is suitable used for the entire study (Foody 2003). To confirm numerical values of bandwidth, we still need to analyze the distribution of data across the study area. Gao et al. (2012a) discussed the potential impacts of GWR results when using smaller or larger bandwidths. Smaller bandwidths produced estimates with a lower risk of bias and larger standard errors correspondingly, as locally weighted regressions were calibrated on a small number of samples. Likewise, the variance of prediction was smaller, but the bias was large when using larger bandwidths (Propastin 2009). Therefore, we calculated the stationarity index at multiple scales to analyze the scale dependence of spatial relationships and the performance of GWR models 
with multiple bandwidths. Gao et al. (2012b) used GWR to model the relationship between NDVI and climatic factors on Qinghai-Tibet Plateau, and the results of univariate regression analyses between NDVI and AMT and AP showed that the relationships tend to stabilize at the scales of 120 and $185 \mathrm{~km}$, respectively. In our study area, however, these two values were 50 and $500 \mathrm{~km}$, respectively. By using the same methods of cross-validation and $\mathrm{AIC}_{\mathrm{c}}$ which we used, Gao et al. (2012b) showed that a bandwidth of $156 \mathrm{~km}$ was suitable for Qinghai-Tibet Plateau, whereas this value was $430 \mathrm{~km}$ in North China. These differences in values reflect that impacts of climatic factors on vegetation had different characteristic spatial scales depending on the specific regions. The magnitude and certain value of this suitable bandwidth might be related with the gradients spatial scales of climate variability of the study area. In our study area, the ecogeographical transition zone is approximately 150 to $450 \mathrm{~km}$ in width. The result also indicated the significance of research and comparison in different geographic regions.

In this study, the results showed that the GWR model had more advantages over the OLS model in many aspects, such as better model performance, lower spatial autocorrelation of residuals, and more precisely predicted NDVI patterns. Gao et al. (2012b) summarized two available methods for characterizing the scale dependence of the NDVI-climate relationship: one was to obtain the data samples of NDVI and climatic factors with a series of different spatial resolutions through polymerization, and establish multiple regression relationships in each subregion; the second was to define the appropriate spatial relationship filter to find the optimum for characterizing the relationship, for instance the GWR model. In our study, the findings are consistent with this argument. We compared the spatial pattern of NDVI predicted by GWR (Fig. 5b) and the spatial pattern estimated by the OLS model in each natural region (Fig. $5 \mathrm{~d}$ and Table 3), and found that both results were quite similar to real spatial patterns. However, the geographical divisions and establishment of separate models implied a huge amount of data and work and were extremely difficult in many cases. Therefore, the study and development of the GWR model has significance in theory and practices, both presently and in the future. The GWR model, of course, was not problem free. One of the deficiencies was that the estimated local coefficients can suffer from the multicollinearity issue (Wheeler and Tiefelsdorf 2005). It assumes spatial nonstationarity for all variables; however, some natural processes and variables may exhibit spatial stationarity in some cases, especially in homogeneous regions (Holt and Lo 2008). Some improvements have been developed to extend the GWR model, such as mixed geographically weighted regression (MGWR) (Mei et al. 2006) and an integrated model of spatially adjusted coefficient processes and Bayesian regression (Wheeler and Calder 2007). In the future, we plan to research the synchronization and dynamic causes of vegetation cover variation and try to enhance the explanatory power and generalization of the GWR model.

\section{Conclusions}

Studies have shown that NDVI-environment relationships always emerge with complex features such as scale dependency and nonstationarity in the highly heterogeneous areas. Considering the strong spatial heterogeneity of climatic conditions in transition zones, the different effects of climate on vegetation between the transition zone and surrounding areas is worth investigating. In this study, we revealed spatial variation and scale-dependent relationships between NDVI and climatic factors in North China, using geographically weighted regression analysis. On the basis of discussions and analysis of appropriate scale in analyzing spatial relations, the results indicated detailed site information on the variable relationships in different parts of the study area, and the spatial relationships were more significant at the ecogeographical transition zone. Since climatic factors are critical for the spatial variations of vegetation on large scales, the vegetation distributions of the ecogeographical transition zone, where located at the northern edge of the East Asian monsoon influences, are very sensitive to climatic conditions, especially strictly restricted by precipitation. In addition, effects of other various factors are worth studying on different scales. Compared with traditional regression models such as OLS, the GWR model yielded more accurate model results and improved model ability to understand the local situation of NDVI. Thus, the local regression method is practical for addressing spatial nonstationary and scale-dependent problems in landscape ecology.

Acknowledgments The research for this study was financially supported by the National Natural Science Foundation of China (nos. 41130534 and 41440747). The authors are grateful to the anonymous reviewers for offering valuable suggestions to improve the manuscript.

\section{References}

Akaike H (1973) Information theory and an extension of the maximum likelihood principle. In: International Symposium on Information Theory, 2nd, Tsahkadsor, Armenian SSR. pp 267-281

Balmford A, Moore JL, Brooks T, Burgess N, Hansen LA, Williams P, Rahbek C (2001) Conservation conflicts across Africa. Science 291(5513):2616-2619

Brunsdon C, Fotheringham S, Charlton M (1998) Geographically weighted regression-modelling spatial non-stationarity. J Roy Stat Soc DSta 47:431-443

Brunsdon C, McClatchey J, Unwin D (2001) Spatial variations in the average rainfall-altitude relationship in Great Britain: an approach using geographically weighted regression. Int J Climatol 21(4):455466 
Calvo E, Escolar M (2003) The local voter: a geographically weighted approach to ecological inference. Am J Polit Sci 47(1):189-204

Chown SL, van Rensburg BJ, Gaston KJ, Rodrigues AS, van Jaarsveld AS (2003) Energy, species richness, and human population size: conservation implications at a national scale. Ecol Appl 13(5):12331241

Cui L, Shi J, Yang Y, FAN W (2009) Ten-day response of vegetation NDVI to the variations of temperature and precipitation in eastern China. Acta Geograph Sin 64(7):850-860

Di Bella C, Rebella C, Paruelo J (2000) Evapotranspiration estimates using NOAA AVHRR imagery in the Pampa region of Argentina. Int J Remote Sens 21(4):791-797

Evans KL, James NA, Gaston KJ (2006) Abundance, species richness and energy availability in the North American avifauna. Global Ecol Biogeogr 15(4):372-385

Fang J, Piao S, Tang Z, Peng C, Ji W (2001) Interannual variability in net primary production and precipitation. Science 293(5536):17231723

Finley AO (2011) Comparing spatially-varying coefficients models for analysis of ecological data with non-stationary and anisotropic residual dependence. Methods Ecol Evol 2(2):143-154

Foody G (2003) Geographical weighting as a further refinement to regression modelling: an example focused on the NDVI-rainfall relationship. Remote Sens Environ 88(3):283-293

Foody GM (2004) Spatial nonstationarity and scale-dependency in the relationship between species richness and environmental determinants for the sub-Saharan endemic avifauna. Global Ecol Biogeogr 13(4):315-320

Fotheringham AS, Brunsdon C, Charlton M (2002) Geographically weighted regression : the analysis of spatially varying relationships. Wiley, Chichester

Gao J, Li S (2011) Detecting spatially non-stationary and scale-dependent relationships between urban landscape fragmentation and related factors using geographically weighted regression. Appl Geogr 31(1):292-302

Gao J, Li S, Zhao Z, Cai Y (2012a) Investigating spatial variation in the relationships between NDVI and environmental factors at multiscales: a case study of Guizhou Karst Plateau, China. Int J Remote Sens 33(7):2112-2129

Gao Y, Huang J, Li S, Li SC (2012b) Spatial pattern of non-stationarity and scale-dependent relationships between NDVI and climatic factors - a case study in Qinghai-Tibet Plateau, China. Ecol Indic 20: 170-176. doi:10.1016/ecolind.2012.02.007

Gaughan AE, Stevens FR, Gibbes C, Southworth J, Binford MW (2012) Linking vegetation response to seasonal precipitation in the Okavango-Kwando-Zambezi catchment of southern Africa. Int $\mathrm{J}$ Remote Sens 33(21):6783-6804. doi:10.1080/01431161.2012. 692831

Guo Z, Wang Z, Song K, Zhang B, Li F, Liu D (2007) Correlations between forest vegetation NDVI and water/thermal condition in Northeast China forest regions in 1982-2003. Chinese J Ecol 26(12):1930-1936

Guo LGL, Ma ZMZ, Zhang LZL (2008) Comparison of bandwidth selection in application of geographically weighted regression: a case study. Can J For Res 38(9):2526-2534

Hijmans RJ, Cameron SE, Parra JL, Jones PG, Jarvis A (2005) Very high resolution interpolated climate surfaces for global land areas. Int $\mathrm{J}$ Climatol 25(15):1965-1978. doi:10.1002/Joc. 1276

Holt JB, Lo C (2008) The geography of mortality in the Atlanta metropolitan area. Comput Environ Urban Syst 32(2):149-164

Hurvich CM, Tsai CL (1989) Regression and time series model selection in small samples. Biometrika 76(2):297-307

Jarlan L, Mangiarotti S, Mougin E, Mazzega P, Hiernaux P, Le Dantec V (2008) Assimilation of SPOT/VEGETATION NDVI data into a sahelian vegetation dynamics model. Remote Sens Environ 112(4):1381-1394. doi:10.1016/j.rse.2007.02.041
Kerr JT, Ostrovsky M (2003) From space to species: ecological applications for remote sensing. Trends Ecol Evol 18(6):299 305

Kottek M, Grieser J, Beck C, Rudolf B, Rubel F (2006) World map of the Koppen-Geiger climate classification updated. Meteorol Z 15(3): 259-263

Lamb EG, Mallik AU (2003) Plant species traits across a riparian-zone/ forest ecotone. J Veg Sci 14(6):853-858

Legendre P (1993) Spatial autocorrelation: trouble or new paradigm? Ecology 74(6):1659-1673

Leung Y, Chang-Lin M, Wen-Xiu Z (2000) Statistical tests for spatial nonstationarity based on the geographically weighted regression model. Environ Plan A 32(1):9-32

Li SC, Gao WM, Zhou QF, Liu FY (2006) Multi-scale spatial analysis on NDVI and topographical factors using wavelet transform. Acta Ecol $\operatorname{Sin} 26(12): 4198-4203$

Li SC, Zhao ZQ, Xie MM, Wang YL (2010) Investigating spatial nonstationary and scale-dependent relationships between urban surface temperature and environmental factors using geographically weighted regression. Environ Model Softw 25(12):1789-1800. doi:10. 1016/j.envsoft.2010.06.011

Li SC, Zhao ZQ, Wang Y, Wang YL (2011) Identifying spatial patterns of synchronization between NDVI and climatic determinants using joint recurrence plots. Environ Earth Sci 64(3):851-859. doi:10. 1007/s12665-011-0909-z

Liu D, Fu N, Fan J (2008) Dynamic change of vegetation cover and its reponse to climate change in recent 20 years in Tianjin area. Ecol Environ 17(2):798-801

Longley PA, Tobón C (2004) Spatial dependence and heterogeneity in patterns of hardship: an intra-urban analysis. Ann Assoc Am Geogr 94(3):503-519

Luck GW (2007) The relationships between net primary productivity, human population density and species conservation. J Biogeogr 34(2):201-212

Maselli F, Chiesi M (2006) Integration of multi-source NDVI data for the estimation of Mediterranean forest productivity. Int J Remote Sens 27(1):55-72

Mei C, Wang N, Zhang W (2006) Testing the importance of the explanatory variables in a mixed geographically weighted regression model. Environ Plan A 38(3):587

Mennis JL, Jordan L (2005) The distribution of environmental equity: exploring spatial nonstationarity in multivariate models of air toxic releases. Ann Assoc Am Geogr 95(2):249-268

Moody A, Johnson DM (2001) Land-surface phenologies from AVHRR using the discrete fourier transform. Remote Sens Environ 75(3): 305-323

Morawitz DF, Blewett TM, Cohen A, Alberti M (2006) Using NDVI to assess vegetative land cover change in central Puget Sound. Environ Monit Assess 114(1-3):85-106

Myneni R, Tucker C, Asrar G, Keeling C (1998) Interannual variations in satellite-sensed vegetation index data from 1981 to 1991 . J Geophys Res 103(D6):6145-6160

Onema JMK, Taigbenu A (2009) NDVI-rainfall relationship in the Semliki watershed of the equatorial Nile. Phys Chem Earth 34(1316):711-721. doi:10.1016/j.pce.2009.06.004

Osborne PE, Foody GM, Suarez-Seoane S (2007) Non-stationarity and local approaches to modelling the distributions of wildlife. Divers Distrib 13(3):313-323. doi:10.1111/j.1472-4642. 2007.00344.x

Peel MC, Finlayson BL, McMahon TA (2007) Updated world map of the Köppen-Geiger climate classification. Hydrol Earth Syst Sci Disc 4(2):439-473

Piao SL, Fang JY, Zhou LM, Guo QH, Henderson M, Ji W, Li Y, Tao S (2003) Interannual variations of monthly and seasonal normalized difference vegetation index (NDVI) in China from 1982 to 1999. J Geophys Res-Atmos 108 (D14) 
Piao S, Mohammat A, Fang J, Cai Q, Feng J (2006) NDVI-based increase in growth of temperate grasslands and its responses to climate changes in China. Glob Environ Chang 16(4):340-348

Propastin PA (2009) Spatial non-stationarity and scale-dependency of prediction accuracy in the remote estimation of LAI over a tropical rainforest in Sulawesi, Indonesia. Remote Sens Environ 113(10): 2234-2242

Propastin P, Kappas M, Erasmi S (2008) Application of geographically weighted regression to investigate the impact of scale on prediction uncertainty by modelling relationship between vegetation and climate. Int J Spat Data Infrastructures Res 3:73-94

Raynolds MK, Comiso JC, Walker DA, Verbyla D (2008) Relationship between satellite-derived land surface temperatures, arctic vegetation types, and NDVI. Remote Sens Environ 112(4):1884-1894

Ross AL, Foster BL, Loving GS (2003) Contrasting effects of plant neighbours on invading Ulmus rubra seedlings in a successional grassland. Ecoscience 10(4):525-531

Shi H, Laurent EJ, LeBouton J, Racevskis L, Hall KR, Donovan M, Doepker RV, Walters MB, Lupi F, Liu J (2006a) Local spatial modeling of white-tailed deer distribution. Ecol Model 190(1): $171-189$

Shi H, Zhang L, Liu J (2006b) A new spatial-attribute weighting function for geographically weighted regression. Can J For Res 36(4):9961005

Sun Y, Guo P (2012) Variation of vegetation coverage and its relationship with climate change in north China from 1982 to 2006. Ecol Environ Sci 21(1):7-12

Sun H, Shen Y, Yu Q, Flerchinger GN, Zhang Y, Liu C, Zhang X (2010) Effect of precipitation change on water balance and WUE of the winter wheat-summer maize rotation in the North China Plain. Agric Water Manag 97(8):1139-1145

Tobler WR (1970) A computer movie simulating urban growth in the Detroit region. Econ Geogr 46:234-240

Udelhoven T, Stellmes M, Del Barrio G, Hill J (2009) Assessment of rainfall and NDVI anomalies in Spain (1989-1999) using distributed lag models. Int J Remote Sens 30(8):1961-1976

Wang J, Xu X, Liu P (1999) Study on land use and population load in inter-distributing area of agricultural and grazing lands in northern China. Res Sci 21(5):19-24

Wheeler DC, Calder CA (2007) An assessment of coefficient accuracy in linear regression models with spatially varying coefficients. J Geogr Syst 9(2):145-166

Wheeler D, Tiefelsdorf M (2005) Multicollinearity and correlation among local regression coefficients in geographically weighted regression. J Geogr Syst 7(2):161-187

Wu Y, Li Z, Wang Y, Luan Q, Tian G (2009) Responses of vegetation index (NDVI) in typical ecological areas of Shanxi Province to climate change. Chinese J Ecol 5:024

Xiao J, Moody A (2004) Trends in vegetation activity and their climatic correlates: China 1982 to 1998. Int J Remote Sens 25(24):56695689

Zhang X, Hu Y, Zhuang D, Qi Y (2009) The spatial pattern and differentiation of NDVI in Mongolia Plateau. Geogr Res-Aust 1:002

Zhao HL, Zhao XY, Zhang TH, Zhou R (2002) Boundary line on agropasture zigzag zone in north China and its problems on ecoenvironment. Adv Earth Sci 17(5):739-748

Zheng D (2008) Research on eco-geographical region systems of China. The Commercial Press, Beijing 